\title{
Evaluation of Sexual Function According to the Size of the Needle Used in Transrectal-Ultrasonography-Guided Prostate Biopsy
}

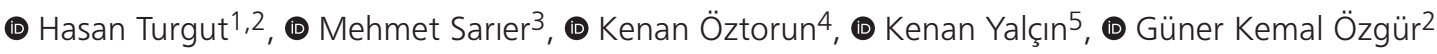 \\ ${ }^{1}$ Avrasya University Faculty of Health Science, Trabzon, Turkey \\ 2Medicalpark Karadeniz Hospital, Clinic of Urology, Trabzon, Turkey \\ 3istinye University Faculty of Medicine, Department of Urology, Istanbul, Turkey \\ ${ }^{4}$ Ömer Halisdemir University Faculty of Medicine, Department of Urology, Niğde, Turkey \\ ${ }_{5}^{5}$ Medicalpark Tokat Hospital, Clinic of Urology, Tokat, Turkey
}

\begin{abstract}
Objective: This study aimed to evaluate the sexual function in patients who underwent a transrectal ultrasonography-guided prostate needle biopsy (TRUS-Bx) using $16 \mathrm{G}$ and $18 \mathrm{G}$ needles.

Materials and Methods: Ninety patients underwent TRUS-Bx. Group 1 included patients who underwent biopsy with an 18G needle ( $\mathrm{n}=45$ ), and group 2 included patients who underwent biopsy with a $16 \mathrm{G}$ needle $(\mathrm{n}=45)$. Sexual function in both groups was prospectively compared. Additionally, the patients' age, prostatespecific antigen (PSA), prostate volume, cancer detection rate, complication rates, visual analog scale (VAS), and International Index of Erectile Function (IIEF) scores were compared.

Results: Age, PSA, prostate volume, cancer detection rate, complication rates and VAS were not found statistically different between the groups. No difference was observed between the two groups in terms of the five main items of IIEF before the procedure. The intercourse satisfaction value was found to be significantly lower after the procedure than before the procedure in group $1(p<0.05)$. Orgasmic function, intercourse satisfaction, and overall satisfaction were statistically significantly lower after the procedure than before the procedure in group $2(p<0.001)$. Orgasmic function and overall satisfaction were lower in group 2 and significantly different between the two groups four weeks after the procedure $(p<0.001)$.

Conclusion: Although erectile function, sexual desire, and intercourse satisfaction were not different on using different needle sizes, in patients where 16G needles were used, orgasmic function and overall satisfaction were lower four weeks after the procedure.
\end{abstract}

Keywords: Prostate biopsy, sexual function, visual analog score

\section{Introduction}

Transrectal ultrasonography-guided prostate biopsy (TRUS-Bx) is the standard for detection of prostate cancer (PCa) (1). TRUS$\mathrm{Bx}$ is mostly preferred due to its short application time, not requiring special equipment, and reusability of the equipment used $(2,3)$. It is not considered a complication-free procedure since $1.0 \%-6.9 \%$ of men who undergo the procedure can experience adverse effects, such as hematuria, hematospermia, dysuria, fever, and septicemia $(0.5 \%-5 \%)(4,5)$. The repercussion of TRUS-Bx for erectile function is not described as one of the main side effects; however, few studies have demonstrated the relationship between erectile function and TRUS-BX. On reviewing the literature, it was shown that the effect of TRUS-Bx on erectile dysfunction (ED) was investigated. In these studies, the short form of International Index of Erectile Function (IIEF) was used $(6,7)$. However, these studies have some limitations, such as using only the short form of IIEF-5 and using only $18 \mathrm{C}$ needle for TRUS-Bx.

This study aimed to evaluate the effect of different sizes of biopsy needles (16G and 18G) on male sexual functions using the IIEF-15 questionnaire, focusing on five main items: erectile function, orgasm function, sexual desire, sexual satisfaction, and overall satisfaction. 
Turgut et al. Evaluation of Sexual Function After TRUS-Bx

\section{Materials and Methods}

An approval was obtained from our institutional review board (number: 2018/01/277) for this study. In this prospective study, all patients who had a suspicious digital rectal examination or high level of prostate-specific antigen (PSA $>4.0 \mathrm{ng} / \mathrm{mL}$ ) who were good candidates for prostate biopsy during the period of February 2018 to March 2020 were evaluated. Ninety patients were included in the study. Demographic data, including age, PSA level, prostate volume, body mass index, cancer detection rate, and complication rates based on TRUS-Bx, were recorded (Table 1). Patients were randomly divided into two groups according to the order of arrival (1:1 ratio). Group 1 included patients who underwent biopsy with an $18 \mathrm{G}$ needle $(n=45)$, and group 2 included patients who underwent biopsy with a $16 \mathrm{G}$ needle $(n=45)$.

No patients were administered a rectal enema on the day before the biopsy. However, all patients received povidone-iodine rectal preparation and were prescribed $1000 \mathrm{mg}$ of ciprofloxacin, divided in two doses, starting $24 \mathrm{~h}$ before the biopsy. The procedure was explained in detail, and all patients signed an informed consent.

All patients were positioned in the lateral decubitus position with knee and hip flexion. Four to five minutes before probe introduction, 2\% lidocaine and chlorhexidine gel were introduced in the patient's rectum and $5 \mathrm{cc}$ lidocaine injections were administered in the right and left periprostatic area. Twelve core biopsies of six right lobes and six left lobes were taken from all patients. The duration of the biopsy was $20 \pm 5$ minutes.

All patients completed the IIEF questionnaire on the day of the biopsy and four weeks after. IIEF evaluates male sexual function using 15 questions. The fifteen questions are as follows: six questions on erectile function, two questions on orgasm function, two questions on sexual desire, three questions on sexual satisfaction, and two questions on overall satisfaction. Additionally, after the biopsy, all patients completed a visual pain score (VAS) assessment. The five main items of IIEF were compared between groups and with each other before the procedure and four weeks after.

Exclusion criteria were patients who used anticoagulants or aspirin in the seven days before the procedure, had any prior prostatic surgery, had any bleeding problem, had any known anal or rectal problems, had any neurological sensory deficit,

Table 1. Demographic, clinical, and pathological data for the two groups

\begin{tabular}{|l|l|l|l|}
\hline & Group 1 & Group 2 & p-value \\
\hline Age (years) & $58.6 \pm 4.2$ & $57.4 \pm 4.5$ & 0.51 \\
\hline PSA $(\mathrm{ng} / \mathrm{mL})$ & $8.76 \pm 3.1$ & $8.4 \pm 4.1$ & 0.46 \\
\hline Prostate volume $(\mathrm{mL})$ & $54.7 \pm 8.2$ & $56.8 \pm 6.9$ & 0.48 \\
\hline Body mass index $\left(\mathrm{kg} / \mathrm{m}^{2}\right)$ & $25.8 \pm 2.9$ & $24.3 \pm 2.7$ & 0.41 \\
\hline Cancer detection rate $(\%)$ & $8 / 45(17.7 \%)$ & $9 / 45(20 \%)$ & 0.89 \\
\hline Gross rectal bleeding & 0 & 0 & \\
\hline Gross hematuria & 0 & 0 & \\
\hline Fever & $2 / 45$ & $2 / 45$ & \\
\hline PSA: Prostate-specific antigen & \multicolumn{5}{|l}{} \\
\hline
\end{tabular}

and scored below the normal value in any of the five main items in the IIEF done before the biopsy.

\section{Sample Size Calculation}

The sample size calculation was performed using G*Power 3.1.9.2 program. It was calculated according to the previous article (8). After considering the alpha level, 0.05, beta error, 0.20 , and the effect size, 0.7 , the total required sample size was calculated as 78. Since the possible drop-out rate was selected as $10 \%, 90$ patients (45 for each group) were recruited as the final sample size for the study before the prospective design.

\section{Statistical Analysis}

Continuous variables were presented as mean \pm standard deviation. Normal distribution was assessed using the Kolmogorov-Smirnov test. Independent groups were analyzed using Student's t-test and Mann-Whitney $U$ test. For normal distribution comparisons between the same groups, Paired-ttest or Wilcoxon Signed-rank test was used when suitable. Data obtained in the study were statistically analyzed using SPSS version 20 (SPSS, Chicago, IL, USA). The significance level was $\mathrm{p}<0.05$.

\section{Results}

Demographic, clinical, and pathological data for the two groups are shown in Table 1. There were no significant differences between the evaluated values of the two groups.

In group 1, erectile function, sexual desire, orgasmic function, intercourse satisfaction, and overall satisfaction were not statistically different after the procedure compared with before the procedure. However, the intercourse satisfaction was significantly lower after the procedure compared with before the procedure $(p<0.05)$. In group 2 , erectile function and sexual desire were not statistically different after the procedure compared with before the procedure. However, orgasmic function, intercourse satisfaction, and overall satisfaction were statistically significantly lower after the procedure than before the procedure $(\mathrm{p}<0.001)$.

No differences were observed between the five main items before the procedure when both groups were compared. However, orgasmic function and overall satisfaction were lower in group 2 and significantly different between the two groups after the procedure $(p<0.001)$ (Table 2$)$. No significant difference was observed between the two groups in terms of VAS $(p=0.14)$.

\section{Discussion}

The findings of this study suggest that the size of the needle used in the biopsy affects the orgasmic function and overall satisfaction. In practice, two sizes of needles (16G and 18G) are used in prostate biopsy. A $16 \mathrm{G}$ needle is approximately 1.5 times wider than an $18 \mathrm{G}$ needle, and the volume of a cylinder (the specimen) is $4 / 3 \pi r 2$ times the length (9). There are many studies in the literature that evaluate the effects of prostate biopsy on $\operatorname{ED}(6,9)$. However, in the literature, male sexual functions have not been evaluated considering the needle size. 
Turgut et al. Evaluation of Sexual Function After TRUS-Bx

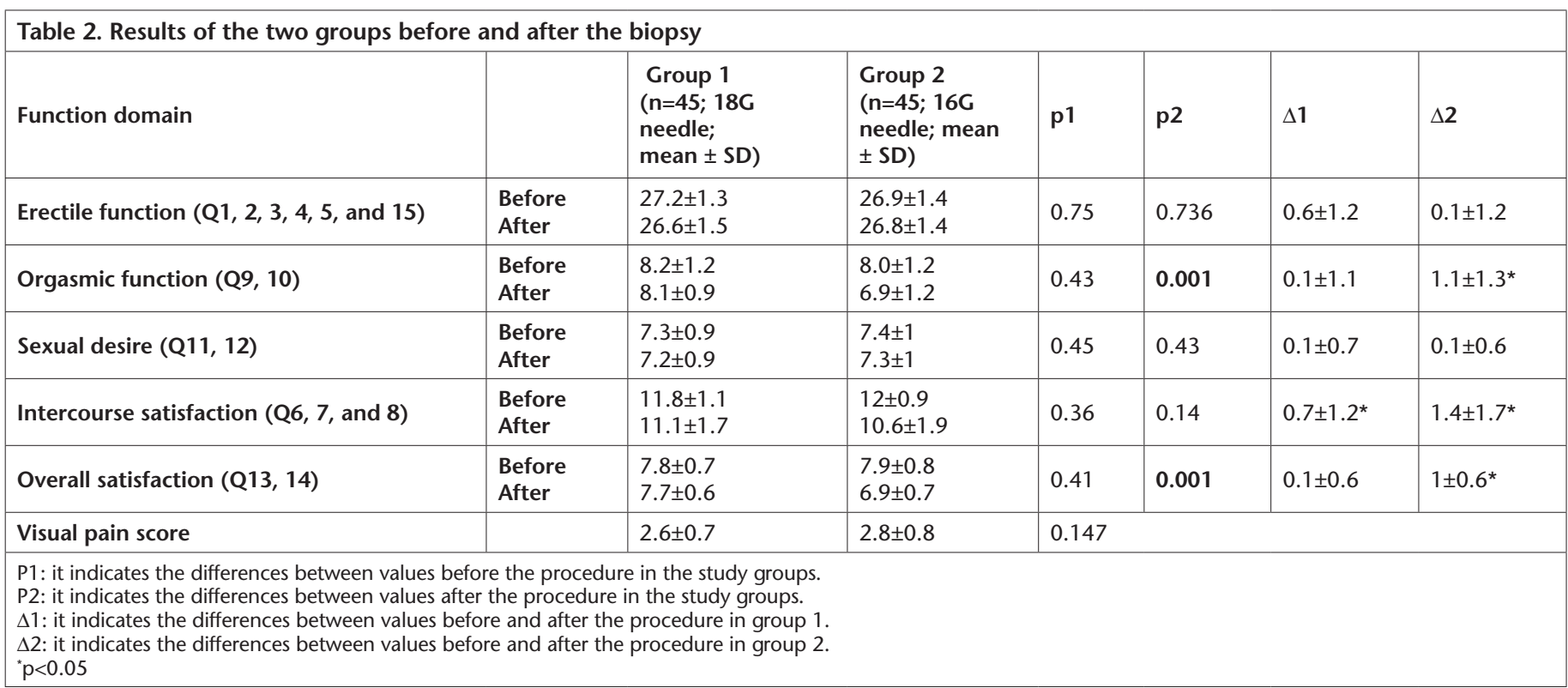

Murray et al. (10) show that, a significant decrease in erectile function score was detected in the first month after prostate biopsy. Similarly, Sönmez et al. (7) showed a significant decrease in erectile function scores at the end of the first month compared with before the procedure. Generally, and as shown in studies, ED presents during the first month after the biopsy. Patients who had a degree of erectile function showed signs of recovery, and the majority of patients returned to their baseline in the long term (10). It is difficult to determine the physiological etiology of ED in a population that undergoes TRUS-Bx, especially those without concomitant ED-related systemic diseases and/ or received medications. ED might be caused by a direct anatomical injury (neurovascular bundle damage) or secondary trauma (nerve compression because of hematoma or edema) (11). Moreover, dilated periprostatic plexus is a common ultrasonography finding in the pathology of the prostate after TRUS-Bx and a frequent cause of ED (12). The two needle sizes used in this study had no effect on erectile function after the procedure compared with before the procedure. However, when both groups were compared in terms of orgasmic function and overall satisfaction values after the procedure, values were significantly lower in group 2 before the procedure. A thicker needle may cause edema in the prostate or hematoma on ejaculation and decrease in intercourse satisfaction and overall satisfaction. The physiopathology causing ED may be the reason for this decrease, and when these patients are evaluated in the long term, these functions may improve.

On evaluating group 1, only the intercourse satisfaction was lower after the procedure compared with before the procedure. Intercourse satisfaction was also lower after the procedure compared with before the procedure in group 2. However, on evaluating the intercourse satisfaction after the procedure, no difference was found between the two groups, which might be related to the approximately similar decreasing values in both groups. On searching the literature, there was no study comparing between orgasmic function, sexual desire, intercourse satisfaction, and overall satisfaction scores in IIEF before and after performing a prostate biopsy. Therefore, we could not compare the scores in our study with other studies.

Due to patients experiencing pain, postprocedure VAS values were compared for sexual dysfunctions. In one study, the use of lidocaine gel combined with periprostatic local anesthesia showed a significant improvement in pain scores compared with lidocaine gel only (13). In our study, we applied local anesthesia with a combination of periprostatic nerve blockage and lidocaine gel for all patients. It was observed that the periprostatic blockade is an effective anesthetic, and no significant difference was observed between the two groups in terms of VAS scores.

One of the strategies for the diagnosis of PCa has been to increase the size of the biopsy needle (14). There are many studies on the relation between cancer detection rate and needle size $(9,14)$. Cicioone et al. (9) and McCormack et al. (14) showed that there were no significant differences between 16G and 18G needles in terms of cancer detection. Similarly, in this study, no differences were seen in the cancer detection rate between the two groups. In TRUS-Bx, the biopsy is obtained through the rectum. Potential risks include infectious complications, such as pyuria, bacteriuria, and fever; hemorrhagic complications including hematuria; relatively minor complications such as vasovagal syncope due to the pain caused by biopsy; major complications, such as structural damage to surrounding anatomical structures and infectious septicemia $(15,16)$. Bleeding after TRUS-Bx is reportedly the most common minor complication (17). In our study, high fever $\left(>38{ }^{\circ} \mathrm{C}\right.$ in two patients) that did not require hospitalization was observed in both groups. No major complications were observed in any patient.

\section{Study Limitations}

There were some limitations in this study. While waiting for a pathology result, there may be changes in IIEF scores due to anxiety occurring in patients. Since this situation is not homogenously distributed, we cannot know which group is affected more. We evaluated the patients in the fourth week, 
but the evaluation in the sixth or twelfth months may provide different results in the long term. The required sample size seemed acceptable in our study. However, the use of samples of a larger size in further research would probably indicate better outcomes.

\section{Conclusion}

Overall, TRUS-Bx did not affect ED. However, on using different needle sizes, significant changes in orgasmic functions and overall satisfaction were observed. It was concluded that using a small needle size is important for sexually active patients.

\section{Acknowledgements}

Publication: The results of the study were not published in full or in part in form of abstracts.

Contribution: There is not any contributors who may not be listed as authors.

Conflict of Interest: No conflict of interest was declared by the authors.

Financial Disclosure: The authors declared that this study received no financial support.

\section{Ethics}

Ethics Committee Approval: An approval was obtained from our institutional review board (number: 2018/01/277) for this study.

Informed Consent: All patients signed an informed consent.

Peer-review: Externally peer-reviewed.

\section{Authorship Contributions}

Concept: H.T., Design: H.T., K.Ö., Data Collection or Processing: H.T., G.K.Ö., Analysis or Interpretation: M.S., Literature Search: K.Ö., K.Y., Writing: H.T.

\section{References}

1. Jiang $C Y$, Shen PF, Wang C, et al. Comparison of diagnostic efficacy between transrectal and transperineal prostate biopsy: a propensity score-matched study. Asian J Androl 2019;21:612-617.

2. Çömez K, Bozkurt O, Mungan MU. Biopsy P, Fusion T. Prostat Biyopsi 2014 : TRUS, MRG / TRUS Füzyon ? Transrektal ? Transperineal ? Bull of Urooncol 2015;128-135.
3. Fabiani A, Servi L, Filosa A, et al. May ultrasound probe size influence pain perception of needle piercing during transrectal prostate biopsy? A prospective evaluation. Arch Ital Urol Androl 2016;88:223-227.

4. Loeb S, Carter HB, Berndt SI, et al. Complications after prostate biopsy: data from SEER-Medicare. J Urol 2011;186:1830-1834.

5. Nam RK, Saskin R, Lee $\mathrm{Y}$, et al. Increasing hospital admission rates for urological complications after transrectal ultrasound guided prostate biopsy. J Urol 2010;183:963-969.

6. Linden-Castro E, Pelayo-Nieto M, Espinosa-Perezgrovas D, et al. The impact of transrectal prostate biopsy on erectile function. Actas Urol Esp 2016;40:453-456. (English, Spanish)

7. Sönmez MG, Kozanhan B, Demirelli E, et al. What should be done to minimize pain without any sexual function deterioration in the transrectal prostate biopsy ? Cent Eur J Urol 2017;372-377.

8. Chrisofos M, Papatsoris AG, Dellis A, et al. Can prostate biopsies affect erectile function? Andrologia 2006;38:79-83.

9. Cicione A, Cantiello F, De Nunzio C, et al. Prostate biopsy quality is independent of needle size: A randomized single-center prospective study. Urol Int 2012;89:57-60.

10. Murray KS, Bailey J, Zuk K, et al. A prospective study of erectile function after transrectal ultrasonography-guided prostate biopsy. BJU Int 2015;116:190-195.

11. Zisman A, Leibovici D, Kleinmann J, et al. The impact of prostate biopsy on patient well-being: A prospective study of pain, anxiety and erectile dysfunction. J Urol 2001;165:445-454.

12. Castellani R, Avogadro A, Quadraccia A. Non invasive detection of venogenic impotence: real-time US evaluation of periprostatic (Santorini's) venous plexus after (PGE1) induced erection. Arch Ital Urol Nefrol Androl 1991;63(Suppl 2):57-60.

13. Turgut H, Aydın HR, Adanur \$̧, ve ark. Transrektal prostat biyopsisinde anestezi seçimi : rektal lidokain jel instillasyonu ve lidokainle periprostatik sinir blokajı karşılaştırması. Yeni Üroloji Dergisi 2014;9:17-21.

14. McCormack M, Duclos A, Latour M, et al. Effect of needle size on cancer detection, pain, bleeding and infection in TRUS-guided prostate biopsies: A prospective trial. J Can Urol Assoc 2012;6:97-101.

15. Rietbergen JBW, Kruger AEB, Kranse R, Schröder FH. Complications of transrectal ultrasound-guided systematic sextant biopsies of the prostate: evaluation of complication rates and risk factors within a population-based screening program. Urology 1997;49:875-880.

16. Webb NR, Woo HH. Antibiotic prophylaxis for prostate biopsy. BJU Int 2002;89:824-828.

17. Anastasiadis A, Zapałat, Cordeiro E, et al. Complications of prostate biopsy. Expert Rev Anticancer Ther 2013;13:829-837. 